\title{
Ameliorative Effect of Probiotic Strains, Lactobacillus Acidophilus and Lactobacillus Bulgaricus Against Acetic Acid-Induced Inflammation in the Mouse Colon
}

\author{
Md Shihab Uddin Sohag ${ }^{1,2}$, Mst. Mahfuza Rahman ${ }^{1,3}$, Mollika Paul ${ }^{1}$, Md. Masud Rana ${ }^{1}$, \\ Ranjan Kumar Barman ${ }^{1}$, Mir Imam Ibne Wahed ${ }^{1}$, Md. Rafiqul Islam Khan ${ }^{1, ~ * ~}$ \\ ${ }^{1}$ Department of Pharmacy, University of Rajshahi, Rajshahi, Bangladesh \\ ${ }^{2}$ Beximco Pharmaceuticals Ltd., Gazipur, Bangladesh \\ ${ }^{3}$ Department of Pharmacy, Comilla University, Comilla, Bangladesh
}

Email address:

md.shihab.us@gmail.com (Md S. U. Sohag),mahfuzarahman@gmail.com (Mst. M. Rahman), mollikapaulpharm@gmail.com(M. Paul), masudranajack453@gmail.com (Md. M. Rana), rkb1976@gmail.com (R. K. Barman),wahed_mir@ru.ac.bd (M. I. I. Wahed),

ph_rafiq@yahoo.com (Md. R. I. Khan)

${ }^{*}$ Corresponding author

\section{To cite this article:}

Md Shihab Uddin Sohag, Mst. Mahfuza Rahman, Mollika Paul, Md. Masud Rana, Ranjan Kumar Barman, Mir Imam Ibne Wahed, Md. Rafiqul Islam Khan. Ameliorative Effect of Probiotic Strains, Lactobacillus Acidophilus and Lactobacillus Bulgaricus Against Acetic AcidInduced Inflammation in the Mouse Colon. American Journal of Life Sciences. Vol. 8, No. 6, 2020, pp. 183-188.

doi: 10.11648/j.ajls.20200806.11

Received: January 13, 2020; Accepted: January 27, 2020; Published: November 23, 2020

\begin{abstract}
Probiotic bacteria with anti-inflammatory properties have the potential to be of therapeutic benefit in inflammatory bowel diseases. The present study was designed to evaluate the effect of feeding low-fat probiotic yogurt containing L. acidophilus and L. bulgaricus on acetic acid-induced inflammation in mouse colon. Inflammatory model that mimics various features of IBDs was induced by a single application of $100 \mu 1$ of $4.5 \%$ acetic acid in Swiss Albino mice. Mice were pretreated orally by $200 \mu \mathrm{l}$ yogurt containing both L. acidophilus and L. bulgaricus for 3 days before induction of inflammation and $200 \mu \mathrm{l}$ yogurt was given orally for a period of 7 days after acetic-acid induction. The body weight, food and water intakes, serum biomarkers, macroscopic and histopathological studies of colon tissues were performed to evaluate the anti-inflammatory effect. Combined administration of both strains prevented the damages of villous and crypts in colon epithelial cells and thus provides unique mucosal protective effects in experimental colitis. In conclusion, feeding low-fat probiotic yogurt containing L. acidophilus and L. bulgaricus prevented or ameliorated the inflammatory conditions that can be beneficial to prevent or lower risks of IBDs and its complications.
\end{abstract}

Keywords: Probiotics, Inflammatory Bowel Diseases, Acetic Acid-induced Inflammation

\section{Introduction}

Inflammatory bowel diseases (IBDs), which comprise ulcerative colitis (UC) and Crohn's disease (CD), affect the gastrointestinal tracts (GIT) with chronic and relapsing inflammation. A well balanced diversity of intestinal microbiota is an important aspect of health. In the healthy state, potentially pathogenic bacteria are kept under control by the non-pathogenic flora, so called colonization resistance. Gut microbiota plays a crucial role in triggering, maintaining, and exacerbating IBDs. Although the etiology of these diseases is still unclear, the main hypothesis is that IBDs are a result of an excessive immune response to endogenous bacteria, which occurs in genetically predisposed individuals [1, 2]. Epithelial integrity of the gut is essential for preventing the invasion of microorganisms and the development of inflammation in intestinal submucosa. The intestinal epithelium is a highly selective barrier that permits the absorption of nutrients from the gut lumen into the circulation and at the same time restricts the passage of harmful and potentially 
toxic compounds $[3,4]$.

The gut microbiota normally presents a barrier to invading organisms, but pathogens often become established when the integrity of the microbiota is impaired through stress, illness, antibiotic treatment, changes in diet, or physiological alterations in the gut. The colonic microbiota affects mucosal and systemic immunity in the host [5]. Gut microbiota influences human health through an impact on the gut defense barrier, immune function, and nutrient utilization and potentially by direct signaling with the gastrointestinal epithelium [6]. Disruption of intestinal barrier integrity (leaky gut) may lead to the penetration of luminal bacterial products into the submucosa to initiate local inflammation [3]. Probiotics, when ingested, produce microbial transformation in the intestinal microbiota and exert several health-promoting properties, including maintenance of the gut barrier function and modulation of the host immune system [7-9]. Modulation of intestinal microbiota by probiotics may be of potential for the amelioration of IBDs.

Probiotics are the live microorganisms, which when ingested, confer health benefits without adversely affecting the host. According to Fuller et al., [10]. Lactobacillus strains meet the criteria of probiotics. Various researchers showed the health benefits of Lactobacillus strains $[11,12]$ in various animal model experiments.

In the present study, we aimed to investigate the antiinflammatory effect of two lactobacillus strains, $L$. acidophilus and L. bulgaricus in acetic acid-induced mouse model by analyzing the histopathological studies of the mouse colon.

\section{Methods}

\subsection{Reagents and Materials}

'Probio' capsule manufactured by Square Pharmaceuticals Ltd., Bangladesh. MRS agar media (Hi Media Laboratories, India), Low fat milk (Pran company ltd., Bangladesh), hematoxylin and eosin (Loba Chemicals Ltd., India) and other reagent grade necessary chemicals were purchased from reliable sources.

\subsection{Collection of Commercial Probiotic Sample and Culture in MRS Media}

Commercial probiotic sample 'Probio' (0.5 gm/capsule) manufactured by Square Pharmaceutical Company Ltd., Bangladesh was collected from the local market. According to manufacturer, Probio contained Lactobacillus acidophilus, Lactobacillus bulgaricus and Bifidobacterium bifidum. Stock solution of probio capsule was cultured in MRS agar media by pour plate culture method as described previously [13]. Briefly, $300 \mu \mathrm{L}$ of inoculum from $1 \times 10^{6}$ dilution of stock solution was mixed with MRS agar medium and transferred into anaerobic jar with an anaerobic kit which provided $\mathrm{CO}_{2}$ and the plates were then incubated $37^{\circ} \mathrm{C}$ for 48 hours. The colonies on the MRS plates were then counted and recorded under J2 Colony counter. MRS medium allowed the growth of lactic acid bacteria (LAB) only.

\subsection{Characterization of Pure Cultures and Preparation of Yogurt}

Two different colonies were selected from previously cultured petri dish and transferred into two new MRS plates and incubated at $37^{\circ} \mathrm{C}$ for $48 \mathrm{hrs}$. After the incubation period, the plates with no contamination were checked for their growth patterns, morphology. The plates with no contamination were selected as pure cultures and designated as $\mathrm{LAB} \mathrm{A}$ and $\mathrm{LAB} \mathrm{B}$. Morphological, physiological and biochemical examination of $\mathrm{LAB} A$ and $\mathrm{LAB} B$ were performed according to the previous report [13] in order to characterize the strains. Yogurt was prepared by inoculating probiotic strains $\mathrm{LAB} A$ and $\mathrm{LAB} B$ separately in low fat UHT liquid milk at $37^{\circ} \mathrm{C}$ for 48 hours.

\subsection{Experimental Animal}

Twenty-four Swiss Albino mice of average weight $32.88 \mathrm{~g}$ and age 6 weeks were purchased from animal centre, Department of Biochemistry and Molecular Biology, Rajshahi University, Rajshahi, Bangladesh. Mice were normal without any prominent gastrointestinal problems such as diarrhea or mucus secretion. They were kept in polypropylene mice cages throughout the study. They were housed in a temperature-controlled $\left(24 \pm 1^{\circ} \mathrm{C}\right)$ room with 60 $70 \%$ humidity and standardized light/dark (12/12 hour) cycles. They were acclimated for 1 week and fed with standard mice diet and tap water ad libitum. The experimental protocols were approved by the Institutional Animal, Medical Ethics, Biosafety and Biosecurity Committee (IAMEBBC) at the Institute of Biological Sciences, University of Rajshahi, Bangladesh.

\subsection{Induction of Inflammation}

After an overnight fasting (receiving nothing except water), $100 \mu \mathrm{L} 4.5 \%$ acetic acid [14-16] ( $\mathrm{pH} 2.3$ ) was slowly infused $5 \mathrm{~cm}$ into the rectal lumen via anus of all mice (except normal control group) through polypropylene cannula (Japan). Mice were kept in trendelenburg position for 30 seconds to prevent leakage during acetic acid administration process. Normal control group was treated with $100 \mu \mathrm{L}$ distilled water instead of acetic acid with the same method.

\subsection{Experimental Design}

Healthy mice were subdivided into four groups of six animals in each group.

Group 1 (Normal group): Animals were received $100 \mu \mathrm{L}$ distilled water instead of acetic acid intrarectally.

Group 2 (Inflammatory group): Animals were received $100 \mu \mathrm{L} 4.5 \%$ acetic acid intrarectally once for a period of three days.

Group 3 (Probiotic treatment group) Animals were 
received $100 \mu \mathrm{L} 4.5 \%$ acetic acid once intrarectally for a period of three days and yogurt that containing Lactobacillus acidophilus and Lactobacillus bulgaricus for a period of another seven days.

Group 4 (Standard treatment group) Animals were treated with prednisolone $(0.25 \mathrm{mg} / \mathrm{kg})[17,18]$ along with $100 \mu \mathrm{L}$ $4.5 \%$ acetic acid once. Prednisolone continued for a period of seven days but acetic acid for three days.

\subsection{Macroscopic Study of Mouse Colon}

At the end of the experimental period, mice were euthanized by chloroform anesthesia and then cervical decapitation. The whole colon was excised from each animal. The length and stool quality was analyzed. Finally opened the colon longitudinally, rinsed with saline solution and mucosal lesions were scored macroscopically.

\subsection{Histopathological Studies of Colon Tissues}

Mid distal colon from each animal was excised and preserved in $10 \%$ neutral buffered formalin was treated according to a standard laboratory protocol. Embedded sections were cut at a size of $5 \mu \mathrm{m}$. Then, slides were deparaffinized in $p$-xylene and rehydrated in changes of ethanol $(100 \%, 90 \%, 80 \%, 70 \%$, and $50 \%)$ and rinsed under tap water. Slides were stained by hematoxylin and counterstained by eosin, mounted in DPX, cover-slipped and viewed under a light microscope (Olympus IX71, Japan) connected to a computer.

\subsection{Statistical Analysis}

Statistical analysis was carried out by using a statistical software package Graph Pad Prism 7.0 (San Diego, CA, USA). All data are presented as the mean \pm SEM (standard error of the mean). Differences among groups were assessed by one- way analysis of variance (ANOVA). Student $t$-test was used for comparison between two groups. Values at $p$ $<0.05$ were considered statistically significant.

\section{Results}

\subsection{Characterization of Probiotic Strains for the Preparation of Yogurt and Subsequent Colony Count}

Morphological, physiological and biochemical examination of probiotics suggested that the isolated strains from the commercial product 'Probio' were Lactobacillus $(L)$ acidophilus (LAB-A) and L. bulgaricus (LAB-B) that all features consistent to previous reports $[19,20]$. This morphological characterization has already been published [21]. After preparation of yogurt by inoculating probiotic strain L. acidophilus or L. bulgaricus in low fat UHT liquid milk at $37^{\circ} \mathrm{C}$ for 48 hours, colonies were counted. The yogurt inoculated by $L$. acidophilus was contained 9.73 billion $\left(9.73 \times 10^{9}\right)$ viable L. acidophilus cells per gram and the yogurt inoculated by $L$. bulgaricus contained 9.57 billion $\left(9.57 \times 10^{9}\right)$ viable $L$. bulgaricus cells per gram.

\subsection{Macroscopic Study}

There was no visible damage in the normal control group treated by distilled water only. In acetic acid-induced colitis mice (AA), visual damage was observed. The colon length and colon diameter was also decreased as compared to normal control group (NC) that was prevented in probiotic and standard treatment group (figure 1). In the normal control mice, there were feces in the regular interval of mice colon but in the inflammatory group mice colon, stool was either soft or in some cases it was absent. Reddish ulceration and lesions were observed in the luminal epithelial layers of the inflammatory mice colon (B) which were less in the case of probiotic (C) and prednisolone (D) treatment group. Food and fluid consumption by the mice were decreased after induction of colitis. But after 2 days, the yogurt protected mice and prednisolone treated mice had improved food and fluid intake (data not shown). Besides, the body weight of the colitis mice were changed (decreased) but not significantly during the seven (7) days experimental period.
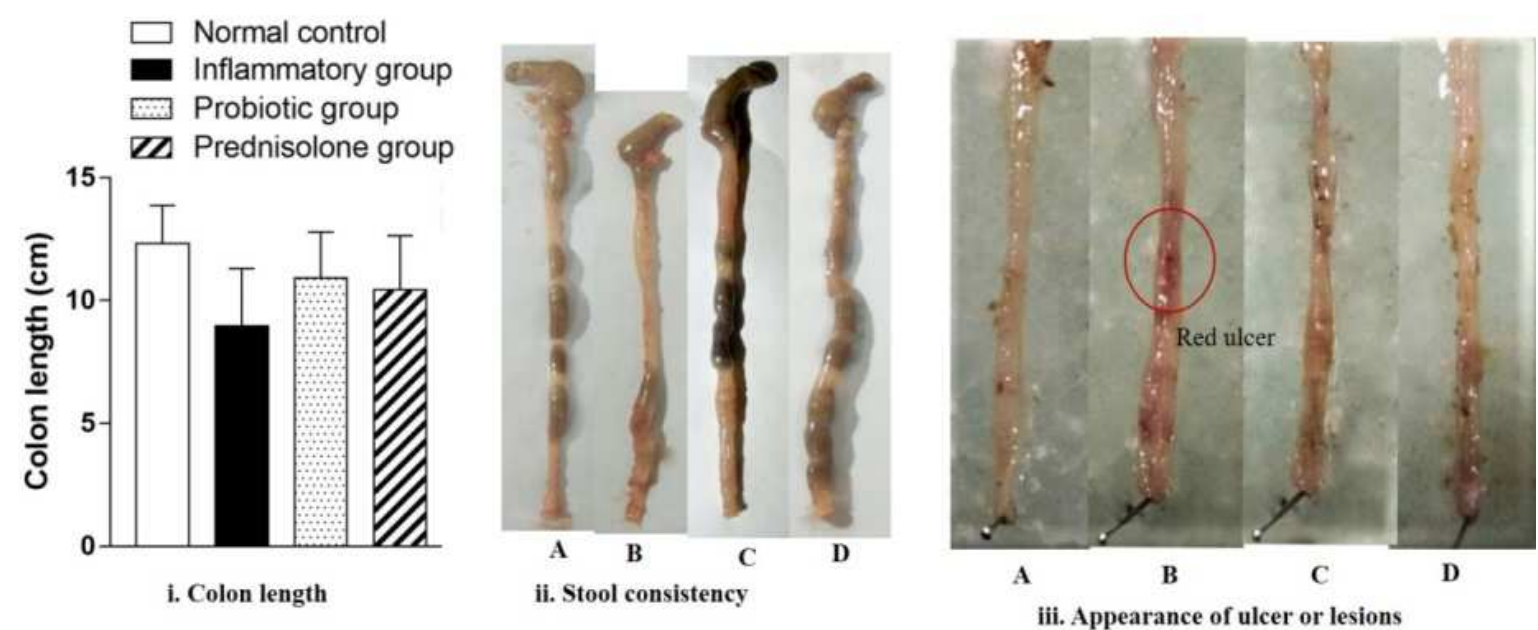

Figure 1. Macroscopic observation of mouse colon; (A) normal control group, (B) inflammatory group, (C) probiotic treatment group, (D) prednisolone treatment group. Inflammation were analyzed by the observation of i) colon length, ii) stool consistency and iii) lesions in the luminal part of colon (red circle). 


\subsection{Histopathological Evaluation of Mouse Colon}

In order to investigate the effect of probiotics on the protection and/or amelioration of acetic acid-induced inflammation, mice colon were fixed with neutral bufferedformalin and stained with hematoxylin and eosin. Microscopic observation showed that acetic acid-induced inflammation caused damages of crypt and villus structure and submucosal edema (figure 2B). Normal control group

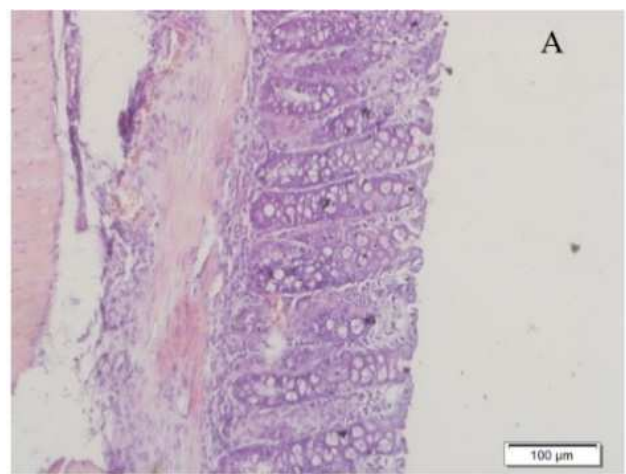

Normal control group

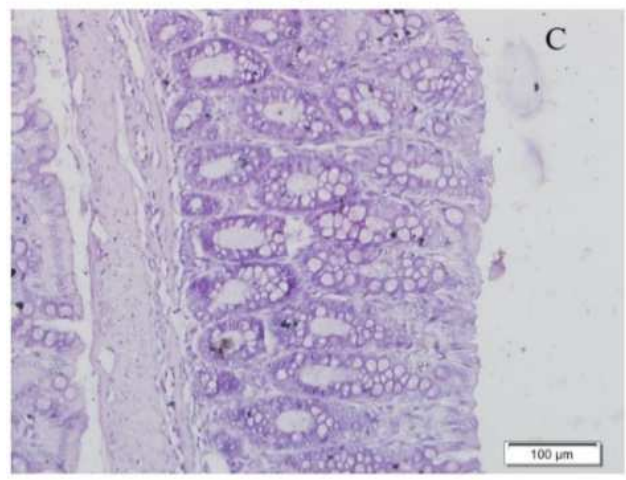

Probiotic treatment group did not show such changes (figure 2A). Administration of probiotic yogurt containing L. acidophilus and L. bulgaricus was not shown the inflammatory cell infiltration and submucosal edema (figure 2C). The epithelial cells with microvilli are almost intact in probiotic protected group. Similar results were observed in the standard prednisolone treatment group (figure 2D).

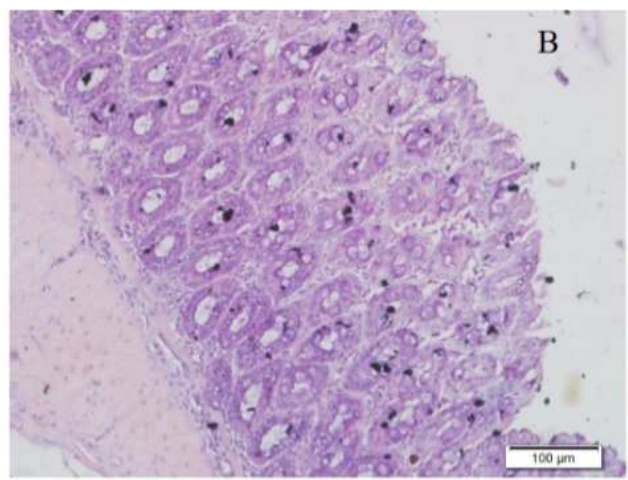

AA-induced inflame. group

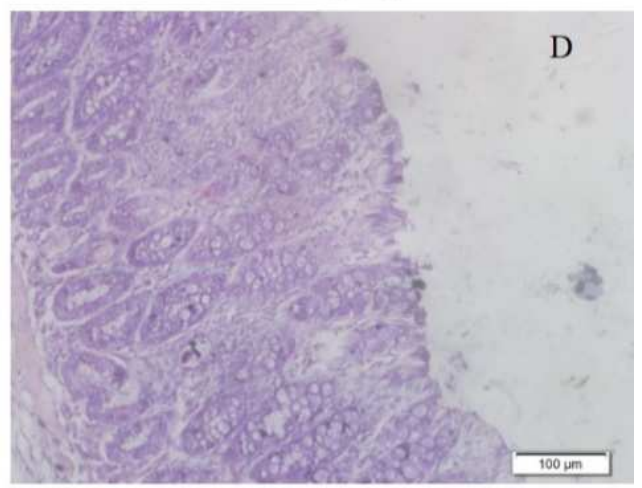

Prednisolone treatment group

Figure 2. Light microscopic (20× magnification) examination of the colonic mucosa in experimental groups. (A) Normal control group, describes normal morphology, regular epithelial line and submucosa; (B) inflammatory group characterized by degenerated surface epithelium, severe submucosal edema, inflammation, vasculitis; (C) probiotic protected group, describes regular epithelial line, well organized submucosa; (D) Standard prednisolone treated group. Scale bar, $100 \mu \mathrm{m}$.

\section{Discussion}

An imbalance between oxidant and antioxidant substances found in acetic acid-induced IBD [22]. It has been well documented that infiltration of neutrophils leads to the production of superoxide anion and initiation of a cascade for the production of various reactive species. This may lead to the generation of hydroxyl radicals and peroxides that significantly contribute to the progression of tissue necrosis and mucosal dysfunction [23, 24]. Evidence has shown that probiotic bacteria present significant antioxidant abilities both in vivo and in vitro [25]. Regular administration of $L$. acidophilus and $L$. bulgaricus might restore the balance between oxidant and antioxidant substances or controlled the infiltrating neutrophils that had a significant contribution to the regulation of inflammation and immune responses in peripheral tissue. Probiotics could modulate intestinal epithelial cells (IEC) function in a variety of ways, including indirect effects on microbial biofilms [26] and direct effects on IECs via enhancement of barrier function by enhancing tight junctions or promoting the epithelial restitution or reorganization of tight junctions and mucin production [27]; induction of antimicrobial peptides (AMPs) and heat shock protein production [28]; modulation of pro-inflammatory and immunoregulatory cytokines and interference with pathogenesis [29].

\section{Conclusion}

In conclusion, administration of low fat yogurt containing L. acidophilus and L. bulgaricus prevented the damages of villous and crypts epithelial cells in the colon and thus 
provides unique mucosal protective effects in experimental colitis. So, our findings indicate that balanced microbiota by L. acidophilus and L. bulgaricus can prevent or lower risks of IBDs and its complications.

\section{Abbreviations}

LAB- lactic acid bacteria; MRS - De Man, Rogosa and Sharpe; PBS-phosphate buffered solution; CFU-colony forming unit; AA- Acetic acid.

\section{Data Availability Statement}

All datasets generated for this study are included in the article/supplementary material.

\section{Author Contributions}

Shohag MSU, Rahman MM, Paul M conducted research. Rana MM, Barman RK analyzed data and drafted of the manuscript. Wahed MII, Khan MRI supervised the project.

\section{Conflict of Interest}

The authors declare no conflict of interest.

\section{Ethical Issue}

Ethical approval and the consent of animal experiment were approved by the Institutional Animal, Medical Ethics, Biosafety and Biosecurity Committee (IAMEBBC) at the institute of biological sciences, University of Rajshahi, Bangladesh.

\section{Acknowledgements}

This work was supported in part by the Ministry of Science and Technology, People's Republic of Bangladesh and Department of Pharmacy, University of Rajshahi. The authors acknowledge to the Department of Biochemistry and Molecular Biology, University of Rajshahi for providing mice.

\section{References}

[1] Natividad J, Verdu E: Modulation of intestinal barrier by intestinal microbiota: pathological and therapeutic implications. Pharmacological Res 2013, 69 (1): 42-51.

[2] Silva HD, Millard P, Soper N, Kettlewell M, Mortensen N, Jewell D: Effects of the faecal stream and stasis on the ileal pouch mucosa. Gut 1991, 32 (10): 1166-1169.

[3] Clayburgh DR, Shen L, Turner JR: A porous defense: the leaky epithelial barrier in intestinal disease. Lab Invest 2004, 84: 282-291.

[4] Hollander D: The intestinal permeability barrier. A hypothesis as to its regulation and involvement in Crohn's disease. Scand J Gastroenterol 1992, 27: 721-726.
[5] Famularo G, Moretti S, Marcellini S, De Simone C: Stimulation of immunity by probiotics. In: Fuller R, ed. Probiotics: therapeutic and other beneficial effects. London: Chapman and Hall, 1997, 13361.

[6] Collado MC, Isolauri E, Salminen S, Sanz Y: The Impact of Probiotic on Gut Health. Current Drug Metabolism 2009, 10: 68-78.

[7] Bermudez-Brito M, Plaza-Díaz J, Muñoz-Quezada S, GómezLlorente C, Gil A: Probiotic mechanisms of action. Ann Nutr Metab 2012, 61: 160-174.

[8] Plaza-Díaz J, Fernandez-Caballero JÁ, Chueca N, Garcia F, Gómez-Llorente C, Sáez-Lara MJ, Fontana L, Gil A: Pyrosequencing analysis reveals changes in intestinal microbiota of healthy adults who received a daily dose of immunomodulatory probiotic strains. Nutrients 2015, 7: 3999-4015.

[9] Plaza-Diaz J, Gomez-Llorente C, Abadia-Molina F, Saez-Lara MJ, Campaña-Martin L, Muñoz-Quezada S, Romero F, Gil A, Fontana L: Effects of Lactobacillus paracasei CNCM I-4034, Bifidobacterium breve CNCM I-4035 and Lactobacillus rhamnosus CNCM I-4036 on hepatic steatosis in Zucker rats. PLoS ONE 2014, 9.

[10] Fuller R: Probiotics in man and animals. J Appl Bacteriol 1989, 66: 365-378.

[11] Abdelouhab K, Rafa H, Toumi R, Bouaziz S, Medjeber O, Touil-Boukoffa C: Mucosal intestinal alteration in experimental colitis correlates with nitric oxide production by peritoneal macrophages: Effect of probiotics and prebiotics. Immunopharmacol Immunotoxicol 2012, 34: 590-597.

[12] Toumi R, Abdelouhab K, Rafa H, Soufli I, Raissi-Kerboua D, Djeraba Z, Touil-Boukoffa C: Beneficial role of the probiotic mixture Ultra biotique on maintaining the integrity of intestinal mucosal barrier in DSS-induced experimental colitis. Immunopharmacol Immunotoxicol 2013, 35: 403-409.

[13] Kumar A, Kumar D: Isolation and characterization of bacteria from dairy samples of Solan in Himachal Pradesh for identification of Lactobacillus spp. Int J Pharm Sci Rev Res 2014, 25 (2): 110-114.

[14] Neurath MF, Fuss I, Kelsall BL, Stüber E, Strober W: Antibodies to interleukin 12 abrogate established experimental colitis in mice. $J$ Exp Med 1995, 182: 1281-1290.

[15] Rachmilewitz D, Karmeli F, Takabayashi K, Hayashi T, Leider-Trejo L, Lee J, Leoni LM, Raz E: Immunostimulatory DNA ameliorates experimental and spontaneous murine colitis. Gastroenterology 2002, 122: 1428-1441.

[16] Niu X, Fan T, Li W, Huang H, Zhang Y, Xing W: Protective effect of sanguinarine against acetic acid-induced ulcerative colitis in mice. Toxicol Appl Pharmacol 2013, 267: 256-265.

[17] Ramana MV, Mukharjee NSV, Ramesh A, Manohar M, Hindu N, Vanaja T, Pavani B, Santhosh N, Srikanth E, Venkatesh $\mathrm{M}$ et al: Effect of Sulfasalazine and Prednisolone against dextran induced ulcerative colitis in female balb/c mice. Journal of Pharmacy Research 2012, 5 (9): 4808-4811.

[18] Triantafillidis JK, Douvi G, Agrogiannis G, Patsouris E, Gikas A, Papalois AE: Effect of Mesalamine and Prednisolone on TNBS Experimental Colitis, following Various Doses of Orally Administered Iron. BioMed Research International 2014, 2014: 8. 
[19] Eckburg PB, Bik EM, Bernstein CN: Microbiology: diversity of the human intestinal microbial flora. Science 2005, 308 (5728): 1635-1638

[20] Sartor RB: Mechanisms of disease: pathogenesis of Crohn's disease and ulcerative colitis. Nature Clinical Practice Gastroenterology and Hepatology 2006, 3 (7): 390-407.

[21] Sohag MSU, Paul M, Al-Bari MAA, Wahed MII, Khan MRI: Potential antidiabetic activities of probiotic strains, L. acidophilus and L. bulgaricus against fructose-fed hyperglycemic rats. Food and Nutrition Sci 2019, 10, 14191432.

[22] Keshavarzian A, Sedghi S, Kanofsky J, List T, Robinson C, Ibrahim C, Winship D: Excessive production of reactive oxygen metabolites by inflamed colon: analysis by chemiluminescence probe. Gastroenterology 1992, 103: 177185 .

[23] Closa D, Folch-Puy E: Oxygen free radicals and the systemic inflammatory response. IUBMB Life 2004, 56: 185-191.

[24] Grisham MB, Granger DN: Neutrophil-mediated mucosal injury. Role of reactive oxygen metabolites. Dig Dis Sci 1988, 33 (3): 6S-15.
[25] Lin MY, Yen CL: Antioxidative ability of lactic acid bacteria. J Agric Food Chem 1999, 47: 1460-1466.

[26] Vastano V, Pagano A, Fusco A, Merola G, Sacco M, Donnarumma G: The Lactobacillus plantarum Eno A1 enolase is involved in immunostimulation of Caco-2 cells and in biofilm development. Adv Exp Med Biol 2016, 897: 33-44.

[27] Zyrek AA, Cichon C, Helms S, Enders C, Sonnenborn U, Schmidt MA: Molecular mechanisms underlying the probiotic effects of Escherichia coli Nissle 1917 involve ZO-2 and PKCzeta redistribution resulting in tight junction and epithelial barrier repair. Cell Microbiol 2007, 9: 804-816.

[28] Schlee M, Harder J, Koten B, Stange EF, Wehkamp J, Fellermann K: Probiotic lactobacilli and VSL\#3 induce enterocyte $\beta$-defensin 2. Clin Exp Immunol 2008, 151: 528535 .

[29] Resta-Lenert S, Barrett KE: Live probiotics protect intestinal epithelial cells from the effects of infection with enteroinvasive Escherichia coli (EIEC). Gut 2003, 52: 988997. 